\title{
Spatially resolved measurement of the spectral emissivity of high-temperature components by multi- channel thermography
}

\author{
by G. Walle, N. Meyendorf, T. Vetterlein, U. Netzelmann, D. Becker and \\ H. Bruns
}

Fraunhofer-Institut für zerstörungsfreie Prüfverfahren (IZFP), 66123 Saarbrücken, Germany

\begin{abstract}
A non-contact pyrometric and thermographic technique for fast measurement of the temperature and emissivity at temperatures up to $1700^{\circ} \mathrm{C}$ was developed. Thermographic images were acquired in five spectral bands. A teaching algorithm was implemented. The system was tested on $\mathrm{SiC}$ and $\mathrm{MoSi}_{2}$ samples.
\end{abstract}

\section{Introduction}

The contactless temperature measurement is based on the fact that all materials emit electromagnetic radiation. The spectrum of this radiation depends on the temperature as well as on the surface properties of the material.

In the case of technical materials the emission coefficient can become strongly dependent on the wavelength (spectral emission coefficient $\varepsilon=\varepsilon(\lambda)$ ). A variation of the surface properties of the material caused by oxidation or a change of the surface roughness may change the spectrum during a measurement. Especially at high temperatures, where chemical and physical processes are going on rapidly, these events should be taken into account during the measurement [1].

Generally applicable correlations of the dependence of the emission coefficient upon temperature and wavelength are not available. One possibility is to measure and to compare the radiation densities in several wavelength ranges with the data measured in a "teach-in" session [2-5]. The multichannel thermography system observes and records the differences between the intensities of radiation in several spectral channels emitted from the sample surface. According to these data, a quantitative dependence of the emission coefficient on the wavelength can be determined.

\section{Setup of a multi-channel thermography system}

Fig. 1 shows the schematic diagram of this device. Here, a parallel arrangement of two IR-cameras observes an area of $50 \mathrm{~mm} \times 50 \mathrm{~mm}$ on the surface of the object at selected wavelengths ranging from 3 to $9.5 \mu \mathrm{m}$. The IR-radiation emitted by the object is reflected by a scan mirror and detected by the IR-cameras via filters set by a positioning system and two mirrors.

After rotating the filter system and positioning the scan mirror in position 1 , the first image is taken. After positioning the scanner on camera 2 the second image is taken. For the acquisition of six single images at different wavelengths this process has to be repeated three times. The total time for one cycle is $500 \mathrm{~ms}$.

Controlling of the filter positioning system and the image acquisition as well as the evaluation of the infrared images was carried out by a menu-driven software package.

\section{Teaching of the camera}

The infrared camera used in this project is working in the two atmospheric windows, namely in the short wave region from 3-5 $\mu \mathrm{m}$ and in the long wave region from 8-12 $\mu \mathrm{m}$. Five 
small band pass filters were selected for spectral emissivity measurements in these radiation bands: $3.3 \mu \mathrm{m}, 3.8 \mu \mathrm{m}, 4.8 \mu \mathrm{m}, 8.5 \mu \mathrm{m}$, and $9.5 \mu \mathrm{m}$. The bandwidth of each filter is five percent of the specified wavelength.

Two kinds of specimens were used in these experiments. One kind of specimen was made by $\mathrm{SiC}$ with a graphite core the other was consisting of $\mathrm{MoSi}_{2}$. The specimens were cylindrical and had a diameter of about $15 \mathrm{~mm}$ and a height of $4 \mathrm{~mm}$. The infrared camera was arranged in a distance of about $40 \mathrm{~cm}$ from the specimens (Fig. 2).

A laser heating technique based on a $\mathrm{CO}_{2}$-laser with a maximum power of $1500 \mathrm{~W}$ was used for the heating of the specimen. A ring-shaped beam mode instead of a Gaussian laser beam mode was applied in order to achieve a more homogeneous heating of the specimen.

The specimen positioned on three tungsten needles was heated with a laser beam radiating onto the specimen surface in normal direction.

The filter positioning system is placed in front of the infrared camera. This camera together with the filter positioning system was used in order to measure the radiation densities at the various wavelengths. Another infrared camera equipped with a telephoto lens with a spatial resolution of $0.1 \mathrm{~mm}$ is used for the temperature measurement. This infrared camera is positioned in such a way that the temperature measurement in the radial bore hole of the cylindrical specimen can be realised. The bore hole has a diameter of $2 \mathrm{~mm}$ and a length of about $7 \mathrm{~mm}$ so that it represents a sufficient approximation for a black body radiator. Numerical calculations according to the unstationary heat diffusion theory are used to correct the surface temperature due to a temperature gradient in the test specimen.

During the heating procedure of the specimens the laser power (in the cw-mode) was increased slowly starting at a low value. In this way a moderate heating speed was achieved avoiding thermally induced stresses inside the specimens. Using different beam power rates various surface temperatures from approximately $1000^{\circ} \mathrm{C}$ to approx. $1700^{\circ} \mathrm{C}$ were generated at the specimen surface. The spectral emissivities in this temperature range are presented in Fig. 3 for $\mathrm{SiC}$ and in Fig. 4 for $\mathrm{MoSi}_{2}$.

\section{Methods for an estimation of temperatures and spectral emissivities}

\subsection{Teach-in technique}

For relevant temperatures $T_{j}$ the spectral radiation densities $S_{j}\left(\lambda_{i}\right)$ are measured for various specimens during the teach-in session. For all temperatures the spectral radiation density data are stored in a data bank together with the estimated surface temperatures $\left(T_{j}\right)$ and the spectral emissivity values calculated from it. So data sets as follows are produced:

$$
\operatorname{Sj}(\lambda 1), \operatorname{Sj}(\lambda 2) \ldots \operatorname{Sj}(\lambda 5) ; \varepsilon j(\lambda 1) ; \varepsilon j(\lambda 2) \ldots \varepsilon j(\lambda 5) ; \mathrm{Tj}
$$

for $\mathrm{j}=1 \ldots \mathrm{n} ; \mathrm{n}$ : number of temperatures.

By training, a characteristic of spectral radiation density behaviour similar to a fingerprint can be found for each material and each temperature.

In the measuring phase it is then possible to estimate the spectral emissivities and the temperature by comparing the actual measured radiation density values (using a least. square algorithm) with the data bank values, which were won during the teach-in phase.

Two different high temperature materials - $\mathrm{SiC}$-graphite and $\mathrm{MoSi}_{2}$ - were examined. First teach-in measurements with the $\mathrm{SiC}$-graphite specimen as well as with the $\mathrm{MoSi}_{2}$ specimen were carried out, as described above, and the radiation density data together with the estimated surface temperatures were stored in a databank.

Later on the measurement was repeated with the SiC-graphite specimen at various laser beam powers and the spectral radiation density images were evaluated. Using the least square algorithm and the taught radiation density values stored in the data bank the spectral emissivities (Fig. 5) as well as the temperatures (Fig. 6) were evaluated pixel by pixel of the image. 
The measurement, calculation and presentation of such spatially resolved spectral emissivity and temperature images take about two seconds for one surface state.

\subsection{Non-selective radiator technique}

A non-selective radiator was assumed for $\mathrm{MoSi}_{2}$ in the emissivity values from $3.3 \mu \mathrm{m}$ and $3.8 \mu \mathrm{m}$ wavelength. That way, the emissivity values from $3.3 \mu \mathrm{m}$ and $3.8 \mu \mathrm{m}$ were equated. According to the Planck's radiation law it was hence possible to calculate from the measured radiation density images for these two wavelengths the temperature distribution on the surface of the $\mathrm{MoSi}_{2}$ specimen.

In this case, it was possible to find an agreement by comparing the temperature in the centre of the specimen surface $\left(1570^{\circ} \mathrm{C}\right)$ and the estimated temperature from the bore-hole temperature measurement $\left(1600^{\circ} \mathrm{C}\right)$. Keeping in mind that the assumption of a non-selective radiator was made, this is a sufficient agreement (see Fig. 4). But there are severe errors in the estimation of the temperature using this non-selective radiator technique if in reality the assumption of equality of the two neighboured emissivity values is not fulfilled.

This case was simulated and the result is that a relatively small deviation from the nonselective radiator assumption of only $4 \%$ has already been generating an error in the temperature estimation of more than $15 \%$.

\section{Summary}

The aim of the study was to measure the spectral emissivities for high temperature materials at elevated temperatures above $1500^{\circ} \mathrm{C}$.

The multi-channel thermographic system has been equipped and tested in the lab for two materials: $\mathrm{SiC}$ and $\mathrm{MoSi}_{2}$.

Spectral emissivities in the wavelength range $3 \mu \mathrm{m}-9.5 \mu \mathrm{m}$ show a dependence on wavelength and temperature for these materials.

It was shown that by a teach-in technique temperature and emissivities of a multichannel image can be calculated pixel by pixel: About one second is needed for a measurement so that this technique can be used to study fast processes where surface properties and emissivities vary as a function of time.

\section{REFERENCES}

[1] BERGMANN-SCHÄFER - Experimentalphysik - Optik, Band 3, 8. Auflage (De Gruyter, Berlin, New York 1987).

[2] SCHIEWE - Mehrkanalpyrometrische Temperaturmessung, VDI-report No. 982,1992, p. 119-125.

[3] KIENITZ - Pyrometrisches Meßverfahren und Mehrkanalpyrometer, German patent, Offenlegungsschrift DE 3611634 A1, (1987).

[4] NORKUS et al. - Multispektralsensor, German patent DE-Offenlegungsschrift P 41334817 (1992).

[5] FISSLER - Möglichkeiten und Grenzen der Mehrwellenlängenpyrometrie als emissionsgradunabhängiges Temperaturmessverfahren. Dissertation Universität Stuttgart, 1990. 
http://dx.doi.org/10.21611/qirt.1998.049

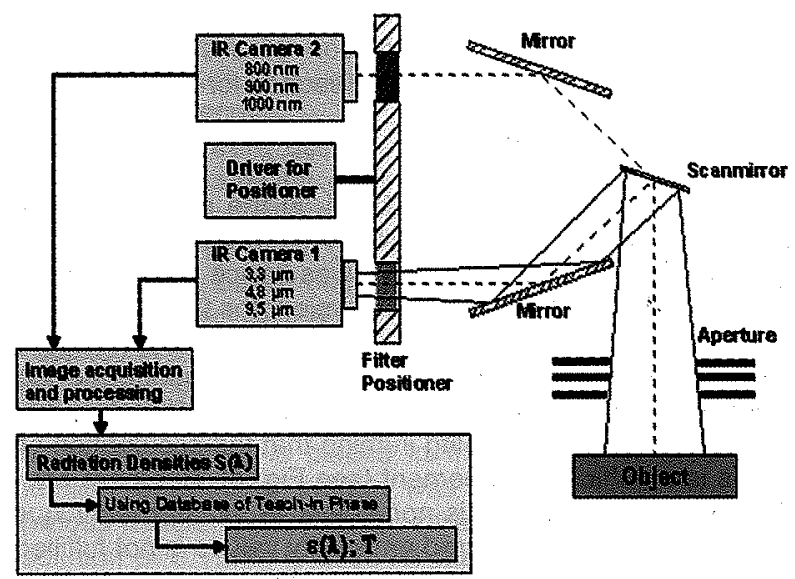

Fig. 1. Setup of the multi-channel thermography system

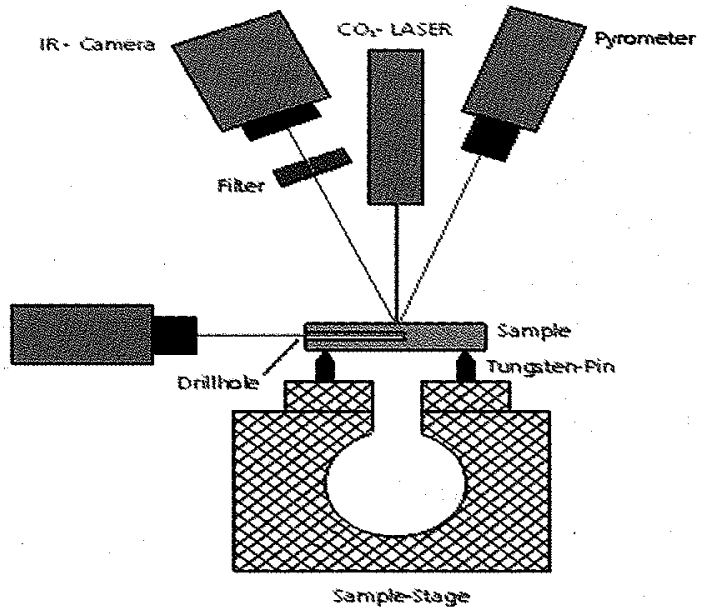

Fig. 2. Measurement arrangement

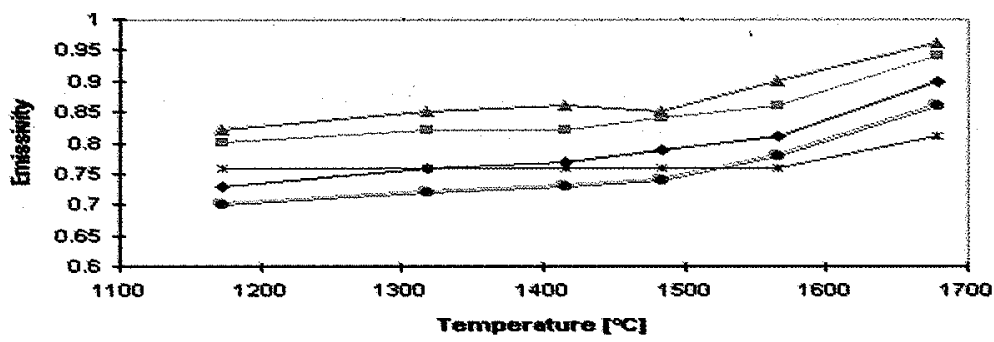

Fig. 3. Emissivity as a function of the temperature for SiC 
http://dx.doi.org/10.21611/qirt.1998.049



Fig. 4. Emissivity as a function of the temperature for MoSi2
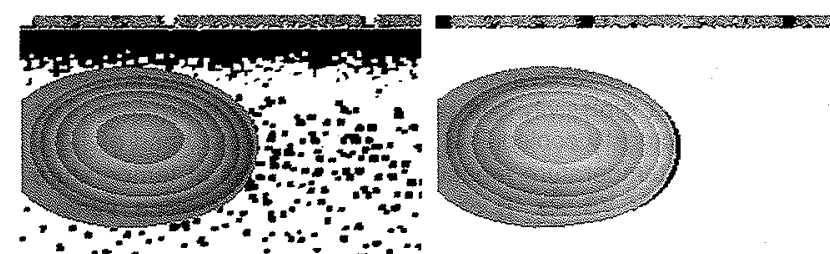

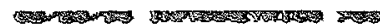





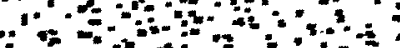

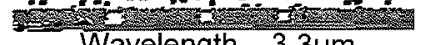

Wavelength $3.3 \mu \mathrm{m}$

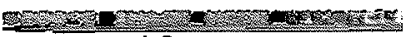

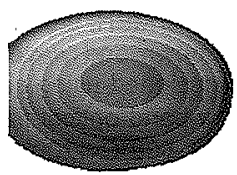

0.0

$4.8 \mu \mathrm{m}$

$\frac{1}{2}$

$8.5 \mu \mathrm{m}$

Fig. 5. Emissivity distribution at specimen surface (SiC-graphite, example)
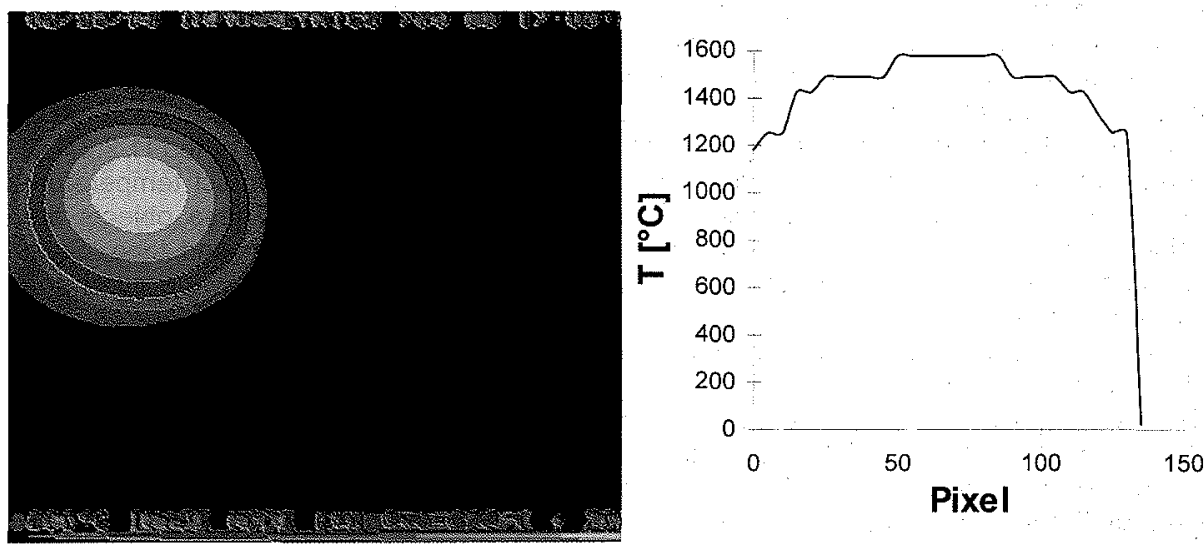

Fig. 6. Temperature distribution at the specimen surface (SiC-graphite) 